\title{
Analisis Status Keberlanjutan Sumber Mata Air Senjoyo pada Dimensi Ekologi dengan Metode RAP-WARES (Rapid Appraissal for Water Resources)
}

\author{
Anggia Agatha Reza, Desti Christian Cahyaningrum*, Susanti Pudji Hastuti \\ Fakultas Biologi, Universitas Kristen Satya Wacana, Indonesia
}

\begin{abstract}
ABSTRAK
Fungsi sumber mata air Senjoyo sebagai kawasan lindung resapan air dan sekitar mata air perlu mendapat prioritas untuk menjamin keberlanjutan sumber mata air Senjoyo. Keberhasilan pengelolaan sumber mata air Senjoyo sebagai kawasan lindung resapan air dan sekitar mata air dapat ditunjukkan dengan status keberlanjutan pada dimensi ekologi. Penelitian ini bertujuan untuk menganalisis status keberlanjutan sumber mata air Senjoyo pada dimensi ekologi. Status keberlanjutan ditentukan berdasarkan indeks keberlanjutan yang dirumuskan melalui metode RAP-WARES (Rapid Appraissal for Water Resources). Penelitian yang dilakukan merupakan penelitian survei dengan data primer dan sekunder yang dikonversi menjadi data kualitatif dalam bentuk skala likert sesuai atribut yang telah disusun. Hasil skoring data ke skala likert kemudian dianalisis dengan teknik Multi-Dimensional Scaling (MDS). Hasil analisis menunjukkan bahwa indeks keberlanjutan Mata Air Senjoyo pada dimensi ekologi adalah sebesar 54.78 dan termasuk dalam kriteria cukup berkelanjutan. Model MDS yang dibangun menghasilkan nilai stress dan nilai $\mathrm{R}^{2}$ berturut-turut sebesar $14,12 \%$ dan 0,948 . Nilai tersebut menunjukkan bahwa keseluruhan atribut yang digunakan dapat mengkaji dengan cukup baik status keberlanjutan kawasan mata air Senjoyo dalam dimensi ekologi. Selisih Indeks Monte Carlo dan Indeks MDS adalah sebesar 0.246 yang membuktikan bahwa kesalahan dalam proses pembuatan skor untuk setiap atribut cenderung kecil, variasi dalam pemberian skor untuk setiap atribut akibat perbedaan pendapat responden relatif kecil, proses analisis yang dilakukan berulang stabil dan kesalahan dalam pemasukan dan kehilangan data dapat dihindari. Berdasarkan hasil analisis sensitivitas, terdapat dua atribut yang paling sensitif yaitu atribut perlindungan terhadap sungai dan mata air (perubahan RMS 3,50\%), dan atribut aktvitas pariwisata (perubahan RMS 3,20\%). Sehingga penelitian ini menyimpulkan bahwa, pengelolaan yang dilakukan masih perlu disesuaikan dengan prinsip pembangunan berkelanjutan, terutama pada aspek perlindungan terhadap sungai dan mata air dan aktivitas pariwisata. Direkomendasikan untuk lebih mengembangkan pariwisata berbentuk ekowisata daripada pariwisata massal untuk menjamin keberlanjutan Sumber Mata Air Senjoyo.
\end{abstract}

Kata kunci: mata air, Senjoyo, keberlanjutan, ekologi, RAPFISH, Multi-Dimensional Scaling

\section{ABSTRACT}

The function of the Senjoyo springs as a water catchment protected area and around the springs needs to be prioritized to ensure the sustainability of the Senjoyo springs. The success of the of Senjoyo springs management as a water catchment protected area and around the springs can be shown by the sustainability status of the ecological dimension. This study aims to analyze the sustainability status of the Senjoyo spring on the ecological dimension. Sustainability status is determined based on the sustainability index that was formulated using the RAP-WARES (Rapid Appraissal for Water Resources) method. This research is a survey research with primary and secondary data which is converted into qualitative data in the form of a Likert scale according to the attributes compiled. The results of scoring the data to a likert scale were then analyzed using the MultiDimensional Scaling (MDS) technique. The results of the analysis shown that the sustainability index of Senjoyo Springs on the ecological dimension is 54.78 and is included in the criteria for being quite sustainable. Stress values and $\mathrm{R}^{2}$ values of the MDS model that was built successively are $14.12 \%$ and 0.948 . This value indicates that all of the attributes that used can properly assess the sustainability status of the Senjoyo spring on the ecological dimension. The difference between the Monte Carlo Index and the MDS Index is 0.246 , which proves that the error in the scoring process for each attribute, the variation in presenting scores for each attribute, and the results of the respondent's disagreement are relatively small. Also, the analysis process that is repeated is stable and errors in data entry and loss can be avoided. Based on the sensitivity analysis, there are two most sensitive attributes, namely the attribute of protection against rivers and springs (change in RMS 3.50\%), and attributes of tourism activities (change in RMS 3.20\%). So, the conclusion of this study is the management that carrying out still needs to be adjusted to the principles of sustainable development, especially in the aspect of protecting rivers and springs and tourism activities. It is recommended to develop tourism in the form of ecotourism instead of mass tourism to ensure the sustainability of Senjoyo Springs.

Keywords: springs, Senjoyo, sustainability, ecology, RAPFISH, Multi-Dimensional Scaling

Citation: Reza, A.A., Cahyaningrum, D.D., dan Hastuti, S.P. (2021). Analisis Status Keberlanjutan Sumber Mata Air Senjoyo pada Dimensi Ekologi dengan Metode RAP-WARES (Rapid Appraissal for Water Resources). Jurnal Ilmu Lingkungan, 19(3), 588-598, doi:10.14710/jil.19.3.588-598

* Penulis korespondensi: desti.cahyaningrum@uksw.edu 


\section{Pendahuluan}

Sumber mata air Senjoyo secara administratif terletak di wilayah pemerintahan Kabupaten Semarang, tepatnya di perbatasan antara Desa Bener dan Tegalwaton. Menurut Rahmawati (2007), kawasan sumber mata air Senjoyo saat ini dikelola dalam tiga fungsi utama yaitu sebagai kawasan lindung resapan air dan sekitar mata air, kawasan pariwisata, serta kawasan budaya untuk pelaksanaan ritual adat setempat. Fungsi kawasan sumber mata air Senjoyo sebagai kawasan lindung resapan air dan sekitar mata air telah disahkan dalam Peraturan daerah kabupaten Semarang Nomor 6 Tahun 2011 Tentang Rencana tata Ruang Wilayah (RTRW) Kabupaten Semarang tahun 2011-2031. Pasal 26 (1) dan (5) dalam RTRW tersebut menyebutkan bahwa "kawasan perlindungan setempat sekitar mata air meliputi kawasan sekurangkurangnya dengan jari-jari 200 meter di sekitar mata air dan pada 125 mata yang tersebar di seluruh kecamatan", termasuk di dalamnya sumber mata Air Senjoyo.

Kawasan sumber mata air Senyojo juga memiliki potensi pariwisata karena banyaknya pengunjung yang datang untuk menikmati pemandangan alam dan sumber mata air, berenang, hingga melakukan aktivitas perkemahan. Hal tersebut ditunjang dengan berbagai fasilitas pariwisata yang tengah berkembang, fasilitas camping ground serta arena untuk pacuan kuda. Kawasan Senjoyo juga memiliki daya tarik tersendiri sebagai kawasan budaya dan kesenian masyarakat, salah satunya dengan rutin diadakanya ritual kungkum pada tanggal-tanggal tertentu. Ritual kungkum diadakan berdasarkan kepercayaan masyarakat setempat bahwa pada zaman dulu kawasan mata air Senjoyo merupakan tempat pertapa dari Joko Tingkir dan dilakukan dengan tujuan untuk memperoleh berkah dan menyongsong datangnya Lailatul Qodar.

Fungsi kawasan Senjoyo melalui ketiga kegiatan tersebut memberikan manfaat yang besar terutama bagi kehidupan masyarakat sekitar; yaitu sebagai sumber air bersih, sarana cagar budaya masyarakat sekitar dan berpotensi sebagai sumber mata pencaharian baru bagi penduduk sekitar melalui pengembangan kawasan pariwisata. Akan tetapi, pemanfaatan sebagai kawasan pariwisata yang tidak ramah lingkungan berpotensi untuk merusak kawasan lindung dan menganggu ekosistem sekitar. Akibatnya, manfaat utama kawasan mata air Senjoyo sebagai sumber air bersih menjadi terancam. Oleh karena itu, fungsi sumber mata air Senjoyo sebagai kawasan lindung resapan air dan sekitar mata air perlu mendapat porsi yang lebih besar.

Fungsi sebagai kawasan lindung resapan air dan sekitar mata air sangat vital mengingat peran utama kawasan tersebut adalah sebagai sumber mata air bersih bagi berbagai wilayah di sekitarnya. Pasokan air bagi sebagian besar kawasan di Salatiga dan
Kabupaten Semarang sangat bergantung dengan sumber mata air Senjoyo. Sumber daya air dari Senjoyo dikelola pemanfaatannya melalui kerjasama oleh berbagai instansi maupun perusahaan seperti Perusahaan Air Minum Daerah (PDAM) Semarang, PDAM kota Salatiga, PT Damatex serta Yonif 411 Salatiga. Pasokan air dari Senjoyo oleh PDAM kota Semarang digunakan untuk memenuhi kebutuhan air di wilayah desa Tegalwaton Kecamatan Tengaran dan Tingkir Tengah wilayah Kota Salatiga. Sedangkan PDAM kota Salatiga menyediakan kebutuhan air bersih untuk sebagai besar wilayah Salatiga dan Kecamatan Tutang. Selain itu, sungai Senjoyo juga dimanfaatkan sebagai air irigasi untuk mengaliri sawah di daerah desa Bener dan Tegalwaton dan pada sebagian besar wilayah Kecamatan Suruh, Pabelan, Brigin dan Bancak Kabupaten Semarang seta pada sebagian kecil wilayah Salatiga.

Keberhasilan fungsi kawasan sumber mata air Senjoyo sebagai kawasan lindung resapan air dan sekitar mata air diasumsikan akan sangat mempengaruhi keberlanjutan sumber mata air tersebut. Sumber mata air yang berkelanjutan dapat tercermin dari eksistensi sumber mata air yang tetap terjaga ditinjau dari beberapa indikator seperti debit air yang selalu tinggi, kualitas air yang baik, serta ekosistem yang terpelihara. Sudarmadji et al (2012) menyatakan bahwa keberlanjutan sumber mata air hanya dapat terwujud melalui pengelolaan yang sesuai dan ditunjang dengan pengawasan dan pemantauan sumber mata air secara berkala. Sejalan dengan hal tersebut, Sudarmadji et al. (2016) kembali menyatakan bahwa pengelolaan mata air tidak terbatas pada aktivitas pemanfaatannya saja namun juga aktivitas pencegahan terhadap kerusakan serta pemeliharaan agar mata air beserta sumbernya tetap terjaga kelestariannya.

Penelitian ini bertujuan untuk mengkaji apakah pengelolaan sumber mata air Senjoyo yang berjalan saat ini telah dapat menunjang keberlanjutan sumber mata air Senjoyo pada dimensi ekologi atau tidak. Status keberlanjutan yang baik pada dimensi ekologi diasumsikan mengindikasikan keberhasilan pengelolaan kawasan sumber mata air Senjoyo sebagai kawasan lindung resapan air dan sekitar mata air. Analisis keberlanjutan sumber mata air Senjoyo pada dimensi ekologi dikaji melalui indeks keberlanjutan kawasan yang dirumuskan melalui pendekatan metode RAP-WARES (Rapid Appraissal for Water Resources). Informasi mengenai status keberlanjutan sumber mata air Senjoyo pada dimensi ekologi dapat bermanfaat dalam meninjau ulang pengelolaan yang ada serta sebagai dasar perumusan strategi pengelolaan yang lebih baik.

\section{Metodologi penelitian}

Penelitian ini merupakan penelitian survei di kawasan sumber mata air Senjoyo, Kabupaten 
Semarang, Jawa Tengah. Secara astronomis, kawasan tersebut terletak di 7022'46"S110³1'39"E. (Gambar 1).

Penentuan indeks keberlanjutan ekologi sumber mata air Senjoyo dalam penelitian ini dilakukan dengan pendekatan metode RAP-WARES (Rapid Appraissal for Water Resources) yang merupakan modifikasi dari metode RAPFISH (Rapid Appraissal for Fisheries). Modifikasi dilakukan pada atribut serta indikator yang digunakan dalam proses skoring. Atribut dan indikator dalam RAP-WARES dirumuskan melalui studi literatur dan disesuaikan dengan kriteria sumber mata air yang berkelanjutan. Sehingga, atribut dan indikator yang digunakan dapat menggambarkan kondisi keberlanjutan kawasan sumber mata air Senjoyo pada dimensi ekologi. Terdapat tiga tahap utama dalam metode tersebut, yaitu perumusan atribut dan indikator, pengumpulan data, proses skoring dan analisis data dengan aplikasi RAPFISH yang ter-adds in di Ms. Excel

\subsection{Perumusan atribut dan indikator}

Perumusan atribut dan indikator dilakukan melalui studi literatur. Atribut dan indikator yang digunakan telah disesuaikan dengan kriteria sumber mata air yang berkelanjutan. Terdapat 10 atribut yang berhasil disusun dalam penelitian ini. Atribut tersebut kemudian dijabarkan dalam beberapa indikator untuk menyusun kuisioner dan pertanyaan wawancara yang hasilnya menjadi data dasar untuk proses skoring (Tabel 1.)

\subsection{Pengumpulan data}

Atribut dan indikator yang telah disusun kemudian diterjemahkan dalam bentuk kuisioner serta daftar pertanyaan wawancara sebagai panduan untuk pengumpulan data. Data primer diperoleh dari pengamatan langsung (observasi), wawancara dan kuisioner, serta analisis sampel air dan makrozoobentos. Responden dalam pengambilan data primer melalui kuisioner dan wawancara dipilih menggunakan teknik purposive random sampling dengan jumlah responden sebanyak 35 orang, karena dengan jumlah responden tersebut informasi yang didapatkan telah jenuh. Responden tersebut dibagi menjadi dua kategori, yaitu responden ahli dan responden awan. Responden ahli dalam penelitian ini adalah pengelola utama, pengelola wahana, Kelompok Sadar Wisata (Pokdarwis), Karang Taruna, Kepala Desa Tegalwaton, Yonif 1411, PT. Damatex, PDAM dan peneliti. Responden awam adalah pengunjung dan masyarakat sekitar. Sementara itu, sampel air diambil di titik sumber mata air yang tidak terjamah aktivitas manusia, sumber mata air terjamah, sumber mata air yang dilindungi, sungai yang banyak orang dan sungai yang jarang orang. Sampel tersebut kemudian dianalisis di laboratorium untuk mengetahui nilai
Biological Oxigen Demand (BOD), Dissolve Oxigen (D0), fosfat, $\mathrm{pH}$ dan suhu. Sampel makrozoobentos juga diambil untuk analisis nilai Famili Biotic Index (FBI). Selain data primer, penelitian ini juga menggunakan data sekunder untuk menunjang analisis dan penarikan kesimpulan. Data sekunder diperoleh dari instansi maupun pemerintah setempat yang berhubungan langsung dengan pengelolaan di kawasan Senjoyo seperti Bappeda, DPU, Dinas LHPE, PDAM, Dinas Pariwisata, Pemerintah kecamatan hingga desa setempat.

\subsection{Proses skoring dan analisis data}

Proses skoring dilakukan dengan mengkonversi data primer maupun sekunder yang diperoleh ke skala likert sesuai dengan indikator pada setiap atribut yang telah disusun. Skala likert yang digunakan adalah 1=buruk, $2=$ sedang, $3=$ baik. Rata-rata skala likert hasil skoring pada setiap atribut kemudian dianalisis dengan aplikasi RAPFISH yang bersifat add-in dalam aplikasi Ms. Excel. Pada dasarnya, analisis data dalam aplikasi tersebut dilakukan menggunakan prinsip Multi- Dimensional Scaling (MDS). MDS merupakan salah satu proses pemetaan atau ordinasi persepsi atau preferensi responden secara visual dalam peta geometri. Perhitungan jarak antar titik acuan dalam proses ordinasi MDS didasarkan pada metode euclidean distance squared dalam ruang berdimensi $\mathrm{n}$ serta dirumuskan sebagai berikut:

Ket: $d=$ jarak geometris (euclidian distance)

$\mathrm{X} 1$ = koordiat $\mathrm{X}$ ke 1, Y1 = koordinat $\mathrm{Y}$ ke 1, dan seterusnya

$$
d=\sqrt{|X 1-X 2|^{2}+|y 1-y 2|^{2}+|Z 1-Z 2|^{2}+\cdots(\text { sejumlah } n)}
$$

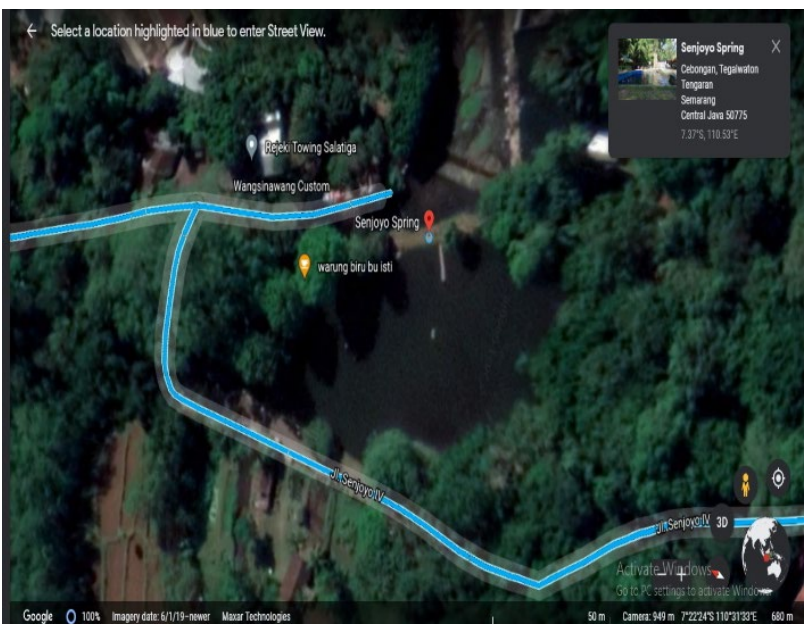

Gambar 1. Lokasi penelitian: Sumber Mata Air Senjoyo (Google earth, 2021) 
Tabel 1. Atribut dan indikator yang digunakan dalam metode RAP-WARES

\begin{tabular}{|c|c|}
\hline 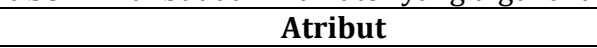 & Indikator \\
\hline Kualitas air sungai & $\begin{array}{l}\text { - BOD (Biological Oxigen Demand) } \\
\text { - Fosfat } \\
\text { - DO (Dissolve Oxigen) } \\
\text { - pH } \\
\text { - suhu } \\
\text { - BFI (Famili Biotic Index) }\end{array}$ \\
\hline Kualitas sumber mata air & $\begin{array}{l}\text { - BOD (Biological Oxigen Demand) } \\
\text { - Fosfat } \\
\text { - DO (Dissolve Oxigen) } \\
\text { - pH }\end{array}$ \\
\hline Dominansi wilayah pembangunan & $\begin{array}{l}\text { - Bentuk pemanfaatan lahan yang mendominasi di wilayah sekitar } \\
\text { - Perkiraan perbandingan luas wilayah yang ditumbuhi vegetasi } \\
\text { terhadap luas wilayah yang digunakan untuk bangunan } \\
\text { - Perkiraan luas wilayah yang didominasi oleh vegetasi pepohonan } \\
\text { - Perkiraan luas wilayah yang didominasi oleh bangunan }\end{array}$ \\
\hline Perlindungan terhadap sungai dan mata air & $\begin{array}{l}\text { - Jarak terdekat bangunan dari tepi sungai di sekitar sumber mata air } \\
\text { - Jarak terdekat bangunan dari tepi sumber mata air } \\
\text { - Ada tidaknya bangunan/konstruksi pelindung bagi titik sumber } \\
\text { mata air }\end{array}$ \\
\hline Aktivitas pariwisata & $\begin{array}{l}\text { - Bentuk aktivitas pariwisata (mass tourism atau ekowisata) } \\
\text { - Kuantitas aktivitas pariwisata yang dapat menumbuhkan } \\
\text { kesadaran lingkungan bagi pengunjung }\end{array}$ \\
\hline Potensi dan tingkat pencemaran & $\begin{array}{l}\text { - Kemudahan ditemukannya fasilitas pembuangan sawah di sekitar } \\
\text { lokasi } \\
\text { - Kuantitas orang yang membuang sampah di lokasi sekitar } \\
\text { - Kuantitas pedagang yang membuang sampah langsung ke sungai } \\
\text { - Peningkatan kuantitas sampah di lokasi sekitar dari hari ke hari } \\
\text { - Kuantitas sampah yang berserakan di lokasi pengamatan } \\
\text { - Ada tidaknya industri yang membuang limbahnya di sungai sekitar }\end{array}$ \\
\hline Kualitas vegetasi & $\begin{array}{l}\text { - Banyaknya area yang ditumbuhi pohon dengan tegakan yang rapat } \\
\text { - Umur pohon di sekitar sumber mata air } \\
\text { - Karekteristik vegetasi yang mendominasi di sekitar sumber mata } \\
\text { air } \\
\text { - Keanekeragaman vegetasi yang tumbuh di sekitar sumber mata air }\end{array}$ \\
\hline Kualitas lingkungan tanah dan perairan & $\begin{array}{l}\text { - Ada tidaknya kejadian tanah longsor dan frekuensinya } \\
\text { - Ada tidaknya kejadian surutnya permukaan sumber mata air dan } \\
\text { frekuensinya } \\
\text { - Ada tidaknya perubahan warna dan aroma air yang berasal dari } \\
\text { sumber mata air serta frekuensinya } \\
\text { - Ada tidaknya kejadian erosi dan frekuensinya } \\
\text { - Ada tidaknya kejadian kekeringan dan frekuensinya } \\
\text { - Ada tidaknya kejadian penurunan debit air di sumber mata air dan } \\
\text { frekuensinya }\end{array}$ \\
\hline Kualitas aktivitas konservasi & $\begin{array}{l}\text { - Ada tidaknya perawatan tanaman di sekitar sumber mata air } \\
\text { beserta frekuensinya } \\
\text { - Ada tidaknya pemantauan kualitas air secara rutin } \\
\text { - Ada tidaknya kegiatan untuk perawatan dan membersihkan } \\
\text { lingkungan sekitar sumber mata air beserta frekuensinya } \\
\text { - Ada tidaknya kegiatan penanaman pohon di sekitar sumber mata } \\
\text { air beserta frekuensinya }\end{array}$ \\
\hline Bentuk aktivitas di sekitar kawasan & $\begin{array}{l}\text { - Ada tidaknya bentuk kegiatan mandi dan mencuci serta } \\
\text { frekuensinya } \\
\text { - Ada tidaknya bentuk kegiatan memandikan ternak serta } \\
\text { frekuensinya }\end{array}$ \\
\hline
\end{tabular}

Sehingga, analisis dengan teknik tersebut menghasilkan grafik dan indeks keberlanjutan hasil ordinasi MDS beserta nilai $\mathrm{R}^{2}$ dan nilai stress-nya. Nilai $\mathrm{R}^{2}$ (koefisien determinasi) menunujukkan validitas model, sedangkan nilai stress menunjukkan proporsi varians yang tidak dijelaskan oleh model. Semakin tinggi nilai stress maka semakin buruk model MDS yang dihasilkan dan berlaku sebaliknya. Indeks keberlanjutan yang dihasilkan dalam proses ordinasi tersebut kemudian dicocokkan dengan kategori keberlanjutan sebagai ditunjukkan pada Tabel 2. 
Tabel 2. Kriteria Keberlanjutan (Susilo, 2003; Hamdan, 2007; Purwaningsih, 2015; Wibowo et al., 2005)

\begin{tabular}{|c|c|}
\hline Nilai Indeks & Kategori \\
\hline $0,00-25,00$ & Tidak bekelanjutan \\
\hline$>25,01-50,00$ & Kurang bekelanjutan \\
\hline$>50,01-75,00$ & Cukup berlanjutan \\
\hline$>75,01-100,00$ & Berkelanjutan \\
\hline
\end{tabular}

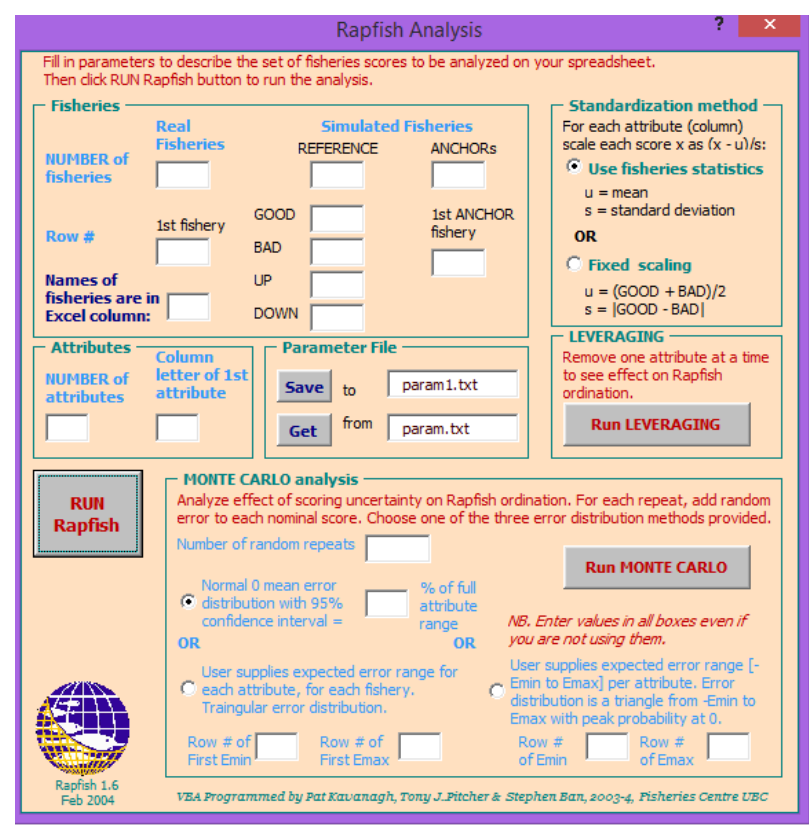

Gambar 2. Aplikasi RAPFISH 1.6. (dok. pribadi, 2021)

Selain menghasilkan indeks keberlanjutan hasil ordinasi MDS beserta nilai stress dan $\mathrm{R}^{2}$ nya, data hasil skoring secara otomatis juga digunakan untuk ordinasi Monte Carlo serta analisis sensitivitas. Kedua analisis tersebut juga dilakukan menggunakan bantuan aplikasi RAPFISH yang telah di-adds in pada Ms. Excel (Gambar 2

Hasil ordinasi Monte Carlo berupa indeks dan grafik Monte Carlo dipergunakan untuk mengkaji pengaruh kesalahan perhitungan maupun kesalahan penilaian terhadap atribut oleh responden. Pada dasarnya, analisis Monte Carlo merupakan suatu analisis berbasis komputasi untuk mensimulasikan unsur peluang dengan pengambilan sampel secara acak. Analisis tersebut bertujuan menentukan variasi acak yang berpengaruh terhadap reliabilitas dari suatu objek yang sedang dimodelkan. Apabila selisih antara rata-rata indeks keberlanjutan Monte Carlo dengan indeks keberlanjutan MDS hasil analisis RAPFISH kurang dari 1, dapat disimpulkan bahwa bahwa pengaruh kesalahan dalam proses analisis dan permodelan secara keseluruhan adalah kecil.

Sedangkan analisis sensitivitas menghasilkan grafik Laverage yang menunjukkan signifikansi pengaruh setiap atribut yang terlihat dari perubahan Root Mean Square (RMS) ordinasi khususnya pada sumbu $x$ atau pada skala accountability. Semakin besar nilai perubahan RMS akibat hilangnya suatu atribut tertentu maka semakin besar pula peranan atribut di dalam pembentukan nilai pada skala keberlanjutan (Pitcher \& Kavanagh, 2004).

\section{Hasil dan Pembahasan}

\subsection{Atribut dalam analisis indeks keberlanjutan sumber mata air Senjoyo}

Penentuan indeks keberlanjutan ekologi sumber mata air Senjoyo dalam penelitian ini dilakukan dengan pendekatan metode RAP-WARES (Rapid Appraissal for Water Resources) yang merupakan modifikasi dari metode RAPFISH (Rapid Appraissal for Fisheries). RAPFISH sendiri merupakan suatu teknik yang dikembangkan oleh University of British Columbia sekitar tahun 1999 untuk mengevaluasi perikanan tangkap secara multidisipliner. Analisis data pada metode RAPFISH pada prinsipnya dilakukan dengan teknik ordinasi dengan Multi-Dimensional Scaling (MDS). MDS telah dikenal secara luas sebagai suatu teknik statistik untuk mentransformasi objek multidimensi yang dikaji kedalam dimensi yang lebih rendah (Mulyana et al., 2011). Menurut Pitcher \& Preikshot (2001), pendekatan MDS dalam RAPFISH memberikan hasil yang stabil dibandingkan dengan metode analisis peubah ganda lainnya.

Metode RAPFISH mencakup beberapa tahapan, yaitu (1) penentuan atribut pada setiap dimensi keberlanjutan, (2) penilaian setiap atribut dalam skala ordinal (proses skoring) berdasarkan kriteria keberlanjutan yang berlaku, serta analisis data yang meliputi (3) penentuan dan analisis indeks keberlanjutan (proses ordinasi) berdasarkan hasil skoring, (4) analisis sensitivitas (laverage analysis) untuk mengetahui atribut yang paling berpengaruh terhadap indeks keberlanjutan, dan (5) analisis Monte Carlo untuk memperhitungkan aspek ketidakpastian. Analiis data berupa tahap ordinasi, analisis sensitivitas, dan analisis Monte Carlo pada teknik RAPFISH, dilakukan secara bersamaan dengan bantuan aplikasi RAPFISH yang telah memiliki template khusus dan di adds-in pada aplikasi Microsoft Excel (Pitcher \& Kavanagh, 2004).

Pada penelitian ini, dilakukan modifikasi pada atribut keberlanjutan yang biasa digunakan dalam RAPFISH. Atribut keberlanjutan adalah pengistilahan untuk objek kajian dalam proses skoring, yang dikelompokkan dalam beberapa dimensi pada metode RAPFISH. Metode RAPFISH pada awalnya dikembangkan untuk mengkaji status keberlanjutan perikanan tangkap, sehingga atribut keberlanjutan untuk perikanan tangkap telah dirumuskan dan digunakan secara umum di berbagai negara sebagai template dalam aplikasi RAPFISH (Pitcher \& Preikshot, 2001). Pada perkembangannya, RAPFISH digunakan untuk mengkaji sumber daya lain diluar perkanan tangkap sehingga atribut-atribut tersebut mengalami penyesuaian berdasarkan kondisi masing-masing sumberdaya yang menjadi objek kajian (Hartono et al., 
2005; Iswari et al., 2008; Raymond et al, 2011). Hal serupa juga terjadi pada penelitian ini. Penentuan indeks keberlanjutan sumber mata air Senjoyo hanya dilakukan pada dimensi ekologi dan menggunakan atribut yang telah disesuaikan dengan kriteria sumber mata air yang berkelanjutan. Penyesuaian atribut tersebut kemudian diistilahkan sebagai metode RAPWARES (Rapid Appraissal for Water Resources), mengingat atribut yang digunakan telah sama sekali berubah dari kriteria perikanan tangkap berkelanjutan menjadi kriteria sumber mata air berkelanjutan. Perubahan template atribut pada aplikasi RAPFISH yang telah di adds-in pada aplikasi Ms. Excel dilakukan secara manual dengan memperhatikan penyesuaian terhadap anchor agar algoritma yang dijalankan sesuai. Sehingga template yang dihasilkan dalam metode RAPWARES (Gambar 3).

Atribut yang digunakan untuk menganalisis pengelolaan yang dijalankan di kawasan Sumber Mata Air Senjoyo antara lain kualitas air sungai, kualitas sumber mata air, dominansi wilayah pembangunan, perlindungan terhadap sungai dan mata air, aktivitas pariwisata, potensi dan tingkat pencemaran, kualitas vegetasi, kualitas lingkungan tanah dan perairan, kualitas aktivitas konservasi, serta bentuk aktivitas di sekitar kawasan (Sudarmadji et al. ,2012; Sihotang.I., et al., 2016; Peraturan Pemerintah Republik Indonesia Nomor 22 Tahun 2021 tentang Penyelenggaraan Perlindungan dan Pengelolaan Lingkungan Hidup; Mandaville, 2002 ; Rahmawati, 2007 ; Peraturan Daerah Kabupaten Tulungagung Nomor 10 Tahun 2012 Tentang Perlindungan Mata Air ; Kodoatie \& Roestam, 2010; Kriteria dan Indikator Pengelolaan Kawasan Lindung dalam Rangka Perwujudan Green Province Jawa Barat, 2012).

Rata-rata hasil skoring tertinggi dihasilkan oleh atribut kualitas air di sumber mata air Senjoyo (skor 3) dan atribut kualitas air sungai (skor 2,83). Hasil skoring tersebut diperoleh melalui penilaian terhadap indikator Biological Oxigen Demand (BOD), Dissolve Oxigen (DO), fosfat, pH dan suhu pada sampel air di beberapa titik sumber mata air dan sungai Senjoyo. Hasil analisis pada semua sampel tersebut menunjukkan bahawa kualitas air sumber mata air dan sungai Senjoyo saat ini masih sesuai dengan baku mutu air nasional kelas 2 yang ditetapkan dalam Peraturan Pemerintah Republik Indonesia Nomor 22 Tahun 2021 tentang Penyelenggaraan Perlindungan dan Pengelolaan Lingkungan Hidup (Tabel 3).

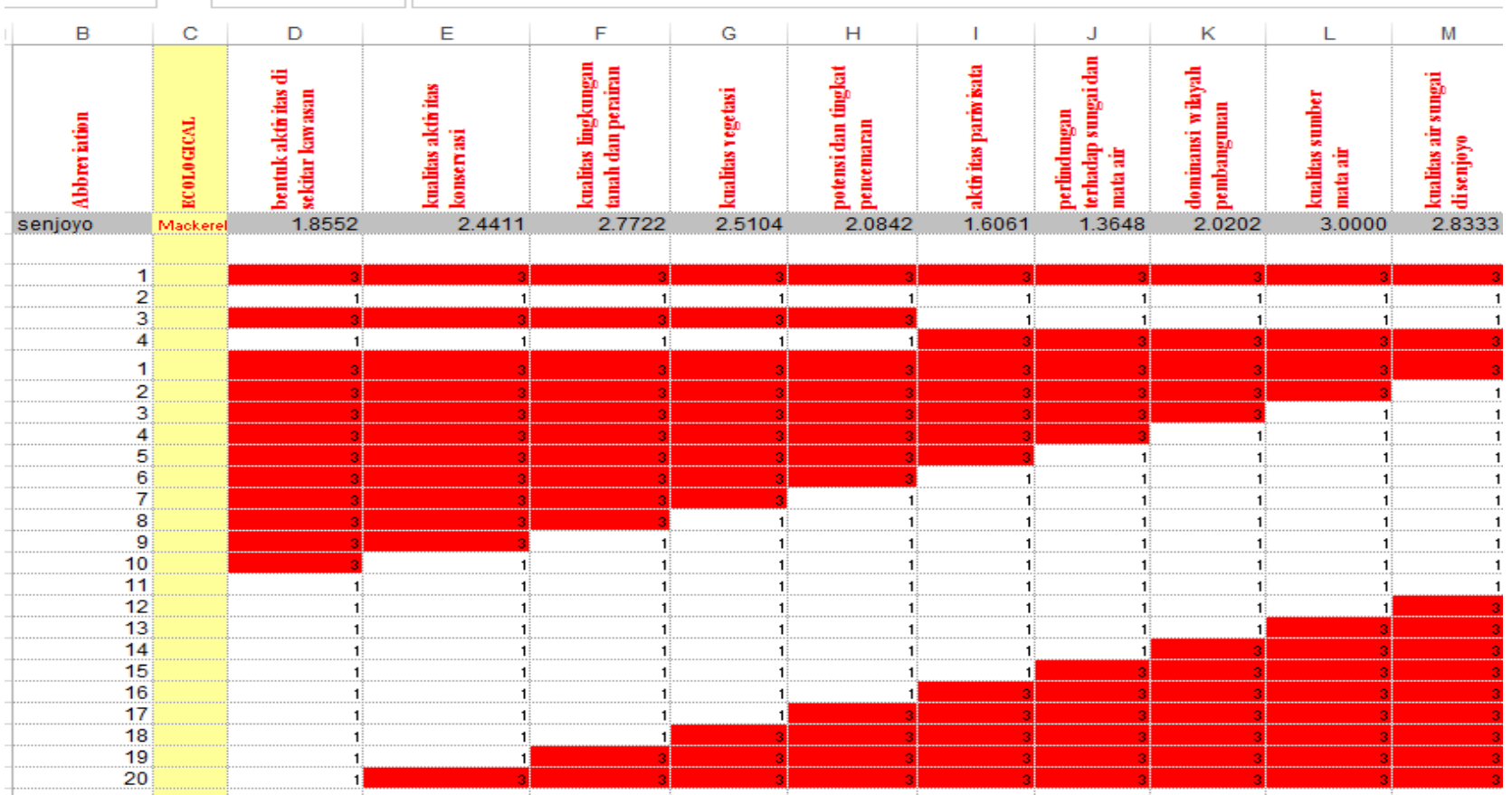

Gambar 3. Template atribut pada RAP-WARES (dok. pribadi, 2021) 
Tabel 3. Hasil analisis sampel air di wilayah sumber mata air Senjoyo (dok. pribadi, 2021)

\begin{tabular}{|c|c|c|c|}
\hline Parameter & \multicolumn{2}{|c|}{ Hasil analisis } & Baku mutu \\
\hline \multirow{5}{*}{ BOD (mg/L) } & Mata air 1 & 0,20 & \multirow{5}{*}{$<3 \mathrm{mg} / \mathrm{L}$} \\
\hline & Mata Air 2 & 0,34 & \\
\hline & Mata Air 3 & 0,19 & \\
\hline & Sungai 1 & 0,49 & \\
\hline & Sungai 2 & 0,91 & \\
\hline \multirow[t]{5}{*}{$\mathrm{DO}(\mathrm{mg} / \mathrm{L})$} & Mata air 1 & 5,5 & \multirow[t]{5}{*}{$>4 \mathrm{mg} / \mathrm{L}$} \\
\hline & Mata Air 2 & 5 & \\
\hline & Mata Air 3 & 5,3 & \\
\hline & Sungai 1 & 5,85 & \\
\hline & Sungai 2 & 5,1 & \\
\hline \multirow{5}{*}{$\begin{array}{l}\text { Fosfat } \\
\text { (mg/L) }\end{array}$} & Mata air 1 & 0,0025 & \multirow[t]{5}{*}{$<0,2 \mathrm{mg} / \mathrm{L}$} \\
\hline & Mata Air 2 & 0,0025 & \\
\hline & Mata Air 3 & 0,0004 & \\
\hline & Sungai 1 & 0,0029 & \\
\hline & Sungai 2 & 0,0042 & \\
\hline \multirow[t]{5}{*}{ Suhu $\left({ }^{\circ} \mathrm{C}\right)$} & Mata air 1 & 24,9 & \multirow{5}{*}{$\begin{array}{lr}\text { Deviasi } & 3 \\
\text { (perbedaan } & \text { suhu } \\
\text { di } & \text { atas } \\
\text { permukaan air ) }\end{array}$} \\
\hline & Mata Air 2 & 22,8 & \\
\hline & Mata Air 3 & 23 & \\
\hline & Sungai 1 & 23 & \\
\hline & Sungai 2 & 25 & \\
\hline \multirow[t]{5}{*}{$\mathrm{pH}$} & Mata air 1 & 6,25 & \multirow[t]{5}{*}{$6-9$} \\
\hline & Mata Air 2 & 6,1 & \\
\hline & Mata Air 3 & 6,15 & \\
\hline & Sungai 1 & 6,5 & \\
\hline & Sungai 2 & 6,3 & \\
\hline
\end{tabular}

Meskipun demikian, sampel makrozoobentos yang didapatkan di sungai sekitar sumber mata air Senjoyo termasuk dalam kelompok Caenidae, Baetidae, Choloroperlidae, Cordulegastridae. Hasil analisis terhadap sampel makrozoobentos tersebut menunjukkan bahwa nilai Family Biotik Index (FBI) pada wilayah tersebut adalah sebesar 5.24 dan termasuk dalam kriteria cukup. Kriteria tersebut menunjukan bahwa sungai di sekitar sumber mata air Senjoyo terpolusi agak banyak bahan organik (Mandaville, 2002 dan Rustiasih et al., 2018).

Selain itu, atribut kualitas lingkungan tanah dan perairan juga memiliki skor yang tinggi, yaitu besar 2,77. Skor tersebut diperoleh berdasarkan data yang menunjukkan bahwa kejadian tanah longsor dan erosi di sekitar mata air sangat jarang terjadi, debit air jarang mengalami penurunan, air permukaan di sekitar sumber mata air jarang surut, tidak pernah terjadi kekeringan di sumber mata air, serta tidak pernah ada perubahan kualitas air yang dilihat dari perubahan warna dan aroma air. Berdasarkan hasil skoring tersebut, maka kualitas air serta lingkungan di sekitar sumber mata air Senjoyo perlu dipertahankan.

\subsection{Keberlanjutan sumber mata air Senjoyo}

Hasil ordinasi MDS menggunakan aplikasi RAPFISH terhadap hasil skoring pada setiap atribut menunjukkan indeks keberlanjutan sebesar 54.78 (Gambar 4). Nilai tersebut menunjukkan bahwa sumber mata air Senjoyo berada dalam kategori cukup berkelanjutan pada dimensi ekologi karena berada pada rentang nilai 50-75 (Thamrin et al, 2007).

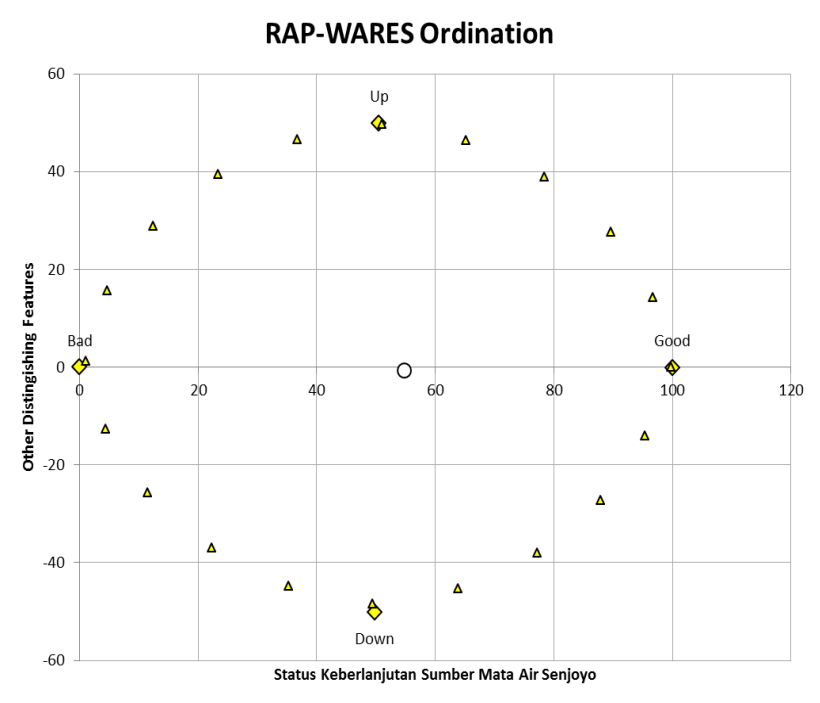

Gambar 4. Hasil ordinasi MDS indeks keberlanjutan Sumber mata air Senjoyo (dok pribadi, 2021)

Nilai stress yang dihasilkan dari ordinasi tersebut menunjukkan nilai yang cukup baik karena tergolong dalam kriteria fair, yaitu sebesar 14,12\%. Nilai stress tersebut mencerminkan Goodness of fit dalam MDS (Pitcher and Preikshot, 2001). Nilai stress menunjukkan proporsi varians yang tidak dijelaskan oleh model. Semakin tinggi nilai stress maka semakin buruk model MDS dan sebaliknya. Kriteria nilai stress dalam penelitian ini meliputi, > 20\% (poor), 10\%-20\% (fair), 5\%-10\% (good), 2,5-5\% (excellent), serta $<2,5 \%$ (perfect) (Simamora, 2005). Sedangkan validitas model ditunjukkan dengan besaran nilai koefisien diterminasi $\left(\mathrm{R}^{2}\right)$. Hasil analisis yang dapat mempresentasikan model dengan baik ditunjukkan oleh nilai $\mathrm{R}^{2}$ yang mendekati 1 atau 100\%. Pada penelitian ini, nilai $\mathrm{R}^{2}$ yang diperoleh adalah 0,948 atau mendekati angka 1 . Nilai stress dan koefisiensi determinasi $\left(\mathrm{R}^{2}\right)$ digunakan untuk mengkaji perlu tidaknya penambahan atribut untuk meningkatkan keakuratan dalam pengkajian masing-masing dimensi. Nilai stress dan $\mathrm{R}^{2}$ yang dihasilkan dalam penelitian ini menunjukkan bahwa keseluruhan atribut yang digunakan dapat mengkaji dengan cukup baik status keberlanjutan kawasan mata air Senjoyo dalam dimensi ekologi.

Pada metode RAP-WARES juga dilakukan analisis sensivitas untuk menentukan atribut yang paling sensitif atau paling berpengaruh dalam membangun indeks keberlanjutan. Signifikasi setiap atibut dianalisis melalui attribute leverging dengan melihat besarnya perubahan Root Mean Square (RMS) pada model MDS yang dibangun jika suatu atribut tertentu dihilangkan dari analisis. Hasil analisis kemudian disajikan dalam grafik laverage. Pada penelitian, berdasarkan grafik leverage (Gambar 5) diketahui terdapat dua atribut yang paling sensitif yaitu atribut perlindungan terhadap sungai dan mata air (perubahan RMS 3,50\%), dan atribut aktvitas pariwisata (perubahan RMS 3,20\%) . 


\section{Leverage of Attributes}

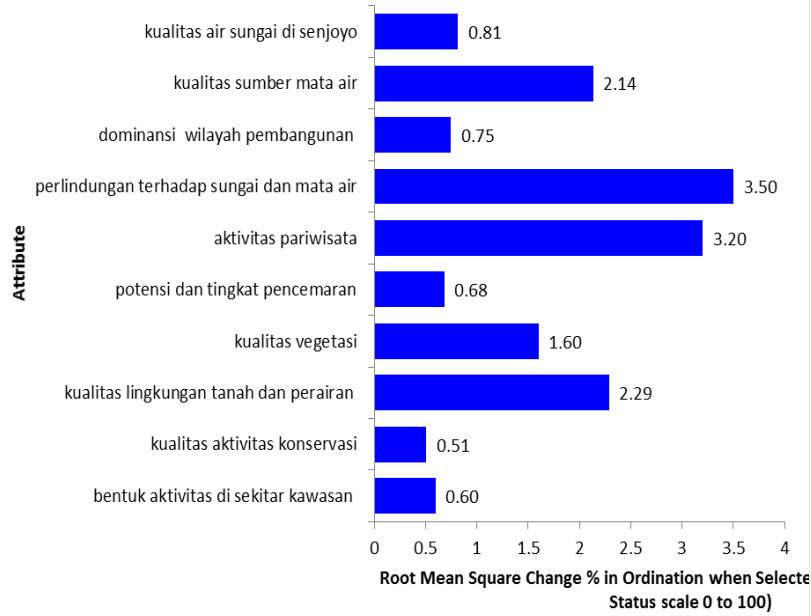

Gambar 5. Grafik Leverage atribut sensitif pada indeks keberlanjutan Sumber mata air Senjoyo (dok pribadi, 2021)

Kedua atribut tersebut yang merupakan faktor paling sensitif yang mempengaruhi keberlanjutan sumber mata air Senjoyo pada dimensi Ekologi. Dengan kata lain, status sumber mata air Senjoyo akan sangat bergantung dengan pengelolaan pada berbagai aspek dalam kedua atribut tersebut

Berdasarkan data hasil observasi, perlindungan terhadap sungai dan mata air berada dalam kriteria kurang baik yang ditunjukkan dengan rata-rata skor untuk semua indikator pada atribut tersebut hanya sebesar 1,43. Hal ini disebabkan karena adanya bangunan maupun fasilitas pariwisata pada radius kurang dari 200 meter dari titik sumber mata air serta kurang dari 50 meter dari sempadan sungai. Di kawasan sumber mata air Senjoyo sangat banyak ditemukan bangunan baik itu semi permanen atau tidak permanen yang dibangun di sekitar sumber mata air bahkan di titik keluarnya sumber mata air, serta di sungai Senjoyo. Hal ini dikawatirkan akan sangat berdampak bagi keberlanjutan sumber mata air dan sungai di kawasan tersebut. Skor pada atribut kualitas air sungai, kualitas sumber mata air,serta kualitas lingkungan tanah dan perairan dikhawatirkan juga akan mengalami penurunan di kemudian hari jika kondisi ini dibiarkan.

Kondisi tersebut juga bertentangan dengan Peraturan Daerah Kabupaten Semarang Nomor 6 tahun 2011 Tentang Rencana tata Ruang Wilayah (RTRW) Kabupaten Semarang Tahun 2011-2031. Pasal 26 (1) dan (5) dalam RTRW tersebut menyebutkan bahwa "kawasan perlindungan setempat sekitar mata air meliputi kawasan sekurang-kurangnya dengan jarijari 200 meter di sekitar mata air “. Artinya, kawasan dengan jari-jari 200 meter dari titik mata air seharusnya difungsikan secara penuh sebagai kawan lindung dan tidak diperuntukkan bagi pembangunan fasilitas pariwisata. Hal ini juga berlaku untuk area dalam radius 50 lima puluh meter dari tepi kiri - kanan sungai yang berada di sekitar sumber mata air Senjoyo, sesuai dengan perda tersebut. Pemasalahan ini dapat diantisipasi dengan adanya penertiban dan penegakkan aturan yang ada oleh pengelola serta didukung oleh kesadaran masyarakat sekitar.

Selain itu, aktivitas pariwisata juga menjadi atribut yang paling sensitif untuk mendukung keberlanjutan sumber mata air Senjoyo. Oleh karena itu, pengelolaan aktivitas pariwisata di kawasan tersebut perlu mendapat perhatian serius. Rata-rata hasil skoring pada atribut aktivitas wisata adalah sebesar 1,61. Artinya, pengelolaan aktivitas pariwisata masih kurang mendukung keberlanjutan sumber mata air Senjoyo. Hal ini diduga karena jenis kegiatan atau aktivitas wisata yang paling mendominasi di sekitar mata air Senjoyo merupakan kegiatan pariwisata massal atau dikenal sebagai mass tourism. Pariwisata massal merupakan bentuk kegiatan pariwisata yang dilakukan oleh banyak orang dalam waktu yang bersamaan. Aktivitas pariwisata yang bersifat massal dikhawatirkan dapat menjadi pemicu utama dalam sumber sampah dan limbah, polusi dan masalah sanitasi yang berdampak buruk bagi lingkungan (Iffa et al. 2015; Sahu et al, 2014).

Apabila pariwisata massal terus dikembangkan di kawasan tersebut, skor atribut potensi dan tingkat pencemaran tentu saja juga akan mengalami penurunan di masa yang akan datang. Hal ini didukung dengan analisis FBI yang menunjukkan bahwa saat ini sungai di sekitar sumber mata air Senjoyo terpolusi agak banyak bahan organik. Polusi tersebut diduga disebabkan oleh limbah sabun dan detergen dalam aktivitas mencuci maupun pariwisata berupa mandi atau berenang. Artinya, status keberlanjutan yang saaat ini berada dalam kategori cukup berkelanjutan mungkin saja berubah menjadi kurang berkelanjutan atau bahkan tidak berkelanjutan dengan penurunan skor tersebut.

Aktivitas pariwisata massal juga dikhawatirkan dapat menjadi penyebab kerusakan ekosistem akibat adanya desakan untuk pembangunan fasilitas dan wahana pariwisata di sekitar mata air Senjoyo. Pembangunan ini akan dirasa sangat perlu dilakukan seiring dengan semakin berkembangnya pariwisata. Padahal, pembangunan tanpa mempertimbangkan aspek konservasi di sumber mata air Senjoyo akan mempengaruhi berbagai aspek dalam atribut keberlanjutan yang lain. Arida (2017) juga menyebutkan bahwa pariwisata massal pada banyak kasus berujung pada kerusakan lingkungan akibat adanya prioritas pada pertumbuhan aspek ekonomi yang tidak jarang mengesampingkan aspek kelestarian lingkungan dan kepentingan masyarakat lokal. Hal ini sering berujung pada pembangunan infrasturktur yang berakibat pada degradasi lingkungan, akibat perusakan sempadan sungai, eksploitasi air tanah, pencemaran lingkungan, dan berbagai hal degradatif lainnya. Hasil observasi Sberkunjung di sumber mata 
air Senjoyo mengakibatkan semakin banyak ditemukannya bangunan semi permanen seperti warung dan wahana permainan air yang berada disekitar kawasan mata air Senjoyo (Gambar 6).

Meningkatnya pembangunan wahana wisata massal pada akhirnya juga dapat menurunkan skor atribut dominansi wilayah pembangunan di masa mendatang. Penurunan tersebut akan diikuti oleh penurunan skor pada atribut kualitas vegetasi, serta kualitas aktivitas konservasi. Hal ini disebabkan karena banyak vegetasi yang akan ditebang serta meluasnya lahan yang diprioritaskan untuk pembangunan. Jika hal tersebut terjadi, fungsi sumber mata air Senjoyo sebagai kawasan lindung resapan air dan sekitar mata air tidak lagi mendapat porsi yang lebih besar. Berkurangnya area vegetasi berdampak pada berkurangnya daerah resapan air yang dapat berdampak buruk pada ketersediaan sumber mata air. Akibatnya, debit air dan kualitas air juga akan mengalami penurunan. Hal ini didukung oleh pernyataan Trimanto (2013) yang menyebutkan bahwa vegetasi di sekitar mata air berperan dalam menjaga kelestarian aliran mata air dan ketersediaan air di kawasan tersebut. Kondisi tersebut tentu saja mengancam keberlanjutan sumber mata air Senjoyo itu sendiri. Romadhan et al. (2020) dalam penelitiannya juga menemukan bahwa pertumbuhan pariwisata beserta pembangunan infrastrukturnya yang masif berdampak terhadap keberlanjutan sumber mata air di Kota Batu akibat adanya perusakan daerah tangkapan air serta pengurangan kuantitas sumber daya air.

Pengelolaan aktivitas pariwisata yang mendukung keberlanjutan sumber mata air Senjoyo dapat dilakukan dengan mengubah bentuk pariwisata massal menjadi ekowisata. Ceballos \& Héctor (1996) mendefinisikan ekowisata sebagai perjalanan mengunjungi daerah yang masih asli dengan bertanggungjawab secara ekologis untuk menikmati dan menghargai keindahan alam dan kebudayaan lokal karena mempromosikan konservasi dalam pelaksanaannya. Ciri khas ekowisata dibandingkan bentuk wiata lainnya adalah adalah adanya aspek konservasi serta pendidikan lingkungan dalam setiap aktivitas wisata yang dilakukan. The International Ecotourism Society (2000) menjabarkan ekowisata sebagai perjalanan wisata alam yang bertanggung jawab dengan melakukan konservasi lingkungan dan meningkatkan kesejahteraan masyarakat lokal. Bentuk pariwisata yang demikian tentu saja dapat mendukung keberlanjutan sumber mata air senjoyo karena adanya aktivitas konservasi yang diintegrasikan dalam kegiatan pariwisata. Ekowisata perairan juga lebih memprioritaskan potensi sumber daya lokal dan meminimalisasi perubahan tata guna lahan maupun tatanan sosial dan budaya mayarakat sekitar (Sunaris, 2019). Sehingga, ketiga fungsi sumber mata air Senjoyo sebagai kawasan lindung resapan air dan sekitar mata air, kawasan pariwisata, serta kawasan budaya untuk pelaksanaan ritual adat setempat akan saling mendukung satu sama lain.
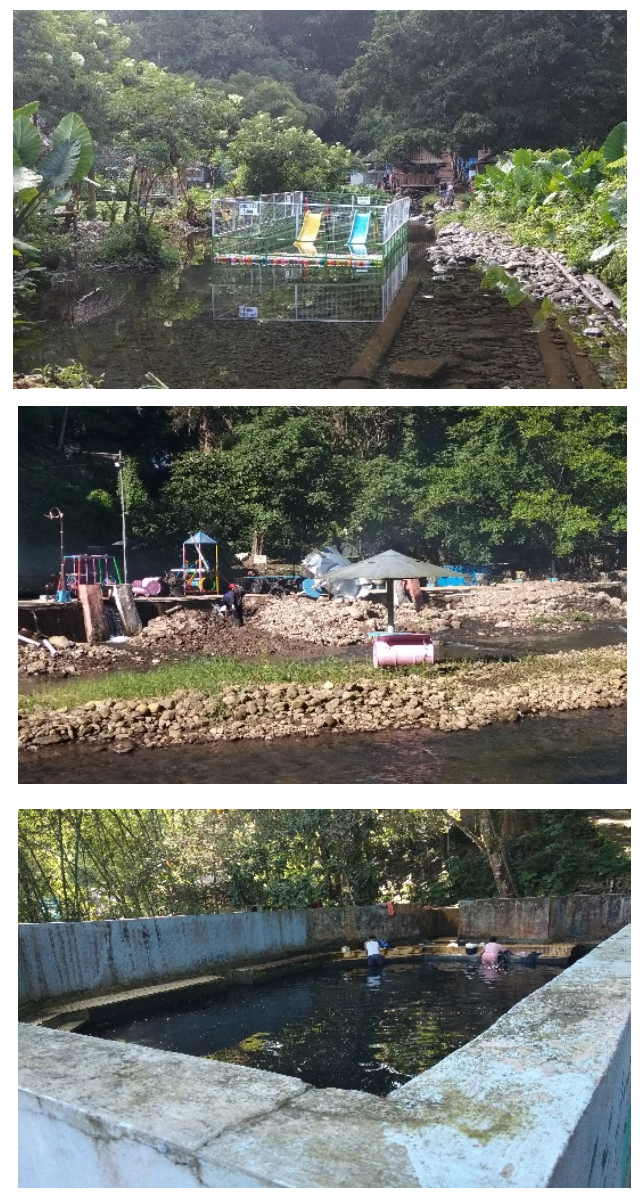

Gambar 6. Bangunan dan wahana wisata di wilayah sekitar sumber mata air Senjoyo (dok pribadi, 2021)

Contoh ekowisata yang dapat diterapkan di sumber mata air Senjoyo adalah paket petualangan river tubing yang diintegrasikan dengan aktivitas penanaman pohon di daerah tangkapan air beserta edukasi mengenai arti penting tanaman bagi sumber mata air. Tentu saja perlu dikaji lebih lanjut berapa kapasitas maksimal pegunjung dalam paket wisata tersebut per harinya yang disesuaikan dengan daya dukung lingkungan yang ada. Contoh lainnya adalah kegiatan susur sungai yang di dalamnya terdapat edukasi mengenai sejarah, arti penting, serta sumber daya alam yang ada di kawasan sumber mata air Senjoyo. Edukasi tersebut dapat dilakukan oleh pemandu wisata sehingga dapat menumbuhkan kesadaran wisatawan untuk menjaga lingkungan di wilayah sekitar sumber mata air Senjoyo. Konsep home stay juga dapat diterapkan untuk akomodasi wisatawan di daerah tersebut dibandingkan akomodasi yang menuntut adanya pembangunan infrastruktur yang masif. 


\subsection{Validitas Hasil Analisis}

Analisis Monte Carlo dalam RAP-WARES dipergunakan untuk mengkaji pengaruh kesalahan dalam proses skoring terhadap atribut akibat keterbatasan informasi, pengaruh variasi pemberian skor akibat perbedaan opini atau penilaian pada atribut oleh setiap responden, stabilitas proses ordinasi MDS, serta kesalahan dalam memasukkan data (Kavanagh, 2001). Penarikan kesimpulan analisis dilakukan dengan membandingkan selisih antara hasil ordinasi pada indeks keberlanjutan Monte Carlo dan Indeks keberlanjutan MDS.

Pada penelitian ini, hasil analisis Monte Carlo yang dilakukansebanyak 25 kali pengulangan (iterasi) pada selang kepercayaan 95\% menunjukkan rata-rata sebesar 54.53 sehingga hanya memiliki selisih sebesar 0.246 dari indeks MDS. Hal ini juga dapat terlihat dari grafik hasil ordinasi Monte Carlo yang mengelompok di sekitar nilai indeks keberlanjutan MDS (Gambar 7). Selisih antara indeks keberlanjutan Monte Carlo dengan indeks keberlanjutan MDS yang kurang dari 1 membuktikan bahwa kesalahan dalam proses pembuatan skor untuk setiap atribut cenderung kecil, variasi dalam pemberian skor untuk setiap atribut akibat perbedaan pendapat responden relatif kecil, proses analisis yang dilakukan berulang stabil dan kesalahan dalam pemasukan dan kehilangan data dapat dihindari (Nurmalina, 2008). Oleh karena itu, proses analisis status keberlanjutan sumber mata air Senjoyo dalam penelitian ini tidak mengandung kesalahan yang signifikan sehingga hasil ordinasi berupa indeks keberlanjutan tersebut berada pada posisi yang baik dan dapat dipertanggungjawabkan.

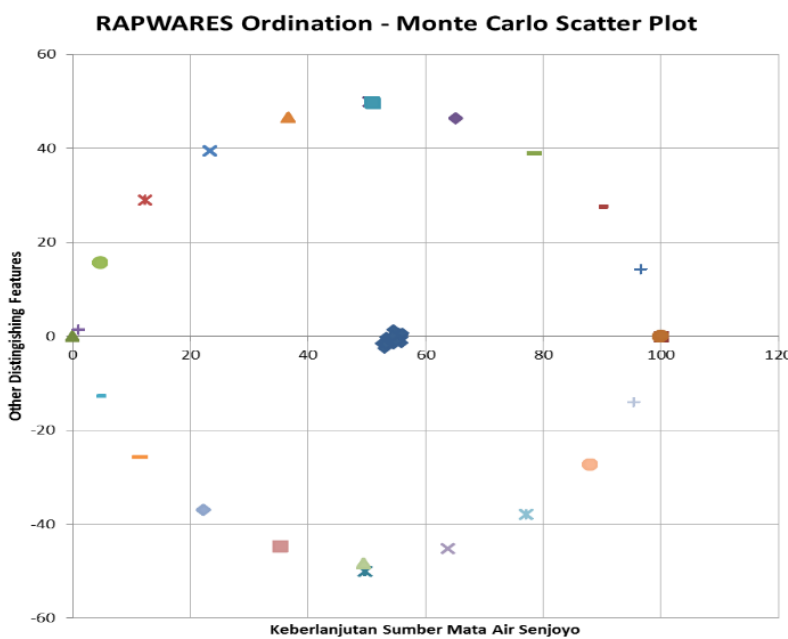

Gambar 7. Analisis indeks Monte Carlo pada analisis keberlanjutan Sumber mata air Senjoyo (dok pribadi, 2021)

\section{Kesimpulan}

Dari penelitian yang dilakukan dapat disimpulkan status keberlanjutan kawasan sumber mata air Senjoyo pada dimensi ekologi termasuk dalam kategori cukup berkelanjutan (indeks keberlanjutan sebesar 54.78). Pengelolaan yang dilakukan terkait dengan atribut perlindungan terhadap sungai dan mata air serta atribut aktivitas pariwisata belum dilakukan berdasarkan prinsip pengelolaan yang mendukung pembangunan berkelanjutan. Sehingga perlu dirumuskan strategi-strategi pengelolaan yang menjamin keberlanjutan kawasan sumber mata air Senjoyo, terutama dalam mendukung fungsinya sebagai kawasan lindung dan resapan air. Bentuk pngelolaan yang direkomendasikan adalah pengembangan ekowisata untuk menjamin keberlanjutan Sumber Mata Air Senjoyo.

\section{DAFTAR PUSTAKA}

Arida, Nyoman Sukma., \& Sunarta, Nyoman., (2017) Pariwisata Berkelanjutan. Bali : Cakra Press.

Ceballos, L. Héctor. (1996). World Conservation Union Tourism, ecotourism, and protected areas : the state of nature-based tourism around the world and guidelines for its development. "CeballosLascuráin, Héctor. Switzerland: International Union for Conservation of Nature.

Dinas Kehutanan Provinsi Jawa Barat \& Sekolah Ilmu Dan Teknologi Hayati ITB. (2012) .Kriteria dan Indikator Pengelolaan Kawasan Lindung dalam Rangka Perwujudan Green Province Jawa Barat, Institut Teknologi Bandung Sekolah Ilmu Dan Teknologi Hayati. 110 hal

Google earth, (2021). Kawasan Sumber Mata Air Senjoyo pada Google Earth. https://earth.google.com. Diakses pada Agusuts 2021.

Hamdan, (2007); Analisis Kebijakan Pengelolaan Perikanan Tangkap Berkelanjutan Di Kabupaten Indramyu. Institut Pertanian Bogor. Bogor

Iffa, N., Nayan, M., Affendy,S., Din, M. (2015). "Significant Indicators in the Assessment of Environmental Tourism Carrying Capacity (ETCC): A Case Study at Royal Belum State Park, Perak Darulridzuan, Malaysia." Tourism \& Environment, Social and Management Sciences. 15:153-60.

Iswari, D., Sutjahjo, S.H., Poerwanto, R., Seta, A. K., dan Bey, A. (2008): Indeks keberlanjutan pengembangan kawasan sentra produksi jeruk berkelanjutan di Kabupaten Agam, Sumatera Barat, J. Hort.18(3):348-359.

Kavanagh, P. (2001). Rapid Appraisal of Fisheries (Rapfish) Project. Rapfish Software Description (for Microsoft Excel). University of British Columbia. Fisheries Centre. Vancouver; Canada. 36p.

Mandaville ,S.M. (2002) Benthic Macroinvertebrates in Freshwaters- Taxa Tolerance Values, Metrics, and Protocols. New York: Soil \& Water Conservation Society of Metro Halifax.

Mulyana, R., J. Haluan., M.S. Baskoro., S.H. Wisudo.(2011): Analisis multidimensional untuk pengelolaan 
perizinan perikanan yang berkelanjutan, studi kasus WPP laut Arafura. Jurnal teknologi perikanan dan Kelautan. 2(1):71-79.

Nurmalina, R. (2007). Model Ketersediaan Beras yang Berkelanjutan untuk Mendukung Ketahanan Pangan Nasional. Program Studi Pengelolaan Sumberdaya Alam dan Lingkungan (PSL). Sekolah Pascasarjana. Institut Pertanian Bogor.

Peraturan daerah kabupaten Semarang Nomor 6 Tahun 2011 Tentang Rencana tata Ruang Wilayah (RTRW) Kabupaten Semarang tahun 2011-2031.

Pemerintah Kabupaten Semarang (2011). Rencana Tata Ruang Wilayah Kabupaten Semarang Tahun 20112031. Semarang. BARENLITBANGDA

Peraturan Pemerintah Republik Indonesia Nomor 22 Tahun 2021 tentang Penyelenggaraan Perlindungan dan Pengelolaan Lingkungan Hidup

Pitcher, T.J., Kavanagh, F. (2004). Implementing Microsoft Excel Software for RAPFISH a Technique For The Rapid Appraisal of Fisheries Status, The Fisheries Centre University of British Columbia. ISSN 1198672.

Pitcher, T.J., Preikshot, D. (2001). RAPFISH: a rapid appraisal technique to evaluate the sustainability status of fisheries. Fisheries Research. 49:255 - 270.

Purwaningsih, (2015). Pengembangan Metode Penilaian Keberlanjutan (Sustainability Assessment) Klaster Industri Perikanan. Fakultas Teknik. Universitas Wahid Hasyim : Semarang

Rahmawati. (2007). "Pemanfaatan Kawasan Sumber Mata Air Senjoyo Dalam Pengembangan Wilayah Di KecamatanTengaran kabupaten Semarang ". Teknik Pembangunan Wilayah dan Kota Program Pascasarjana. Universitas Diponegoro:Semarang

Raymond, M., Yanuar, M.J.P., Hartoyo, S., Sapei, A., Wayan, I.A. (2011). Analisis Keberlanjutan Pengelolaan Air Baku DAS Babon (Studi Kasus di Kota Semarang). Jurnal Rekayasa Lingkungan. 7(2):193-204

Romadhan, A.A., Haryanti, W. Taqwa, I., Nurkhanifah, L. (2020). Political Ecology Protection spring water in Batu. Jurnal of Local Government Issue. 8(1): 75-85)

Rustiasih, E., Arthana, I. W., \& Sari, A. H. W. (2018). Keanekaragaman Dan Kelimpahan Makroinvertebrata Sebagai Biomonitoring Kualitas Perairan Tukad Badung, Bali. 8.

Sahu. Sonam. Nair, S.J. Sharma, P.K. (2014). "Review on Solid Waste Management Practicein India : A State of Art."
International Journal of Innovative Research \& Development 3(3):261-64.

Sihotang.I.V, Sudarmadji, Ig.L.Setyawan Purnama, M. Baiquni. (2016). Model Konservasi Sumber .Daya Air Dalam Upaya Mempertahankan Air Dalama Sub Das Aek Silang. Universitas UMG: Yogyakarta

Santoso, Singgih. (2015). Menguasai Statistik Multivariat. Jakarta : PT Elex Media Komputindo.

Sudarmadji, Suyono, Darmanto, D. (2012).Pengelolaan Sumberdaya Air BerbasisKearifan Lokal Masyarakat Pedesaan di Daerah Fisiografi Gunungapi dan Daerah Fisiografi Karst. Laporan Penelitian. Sekolah Pascasarjana UGM, Yogyakarta.

Sudarmadji , D. Darmanto, M. Widyastuti1 dan S. Lestari (2016). Pengelolaan Mata Air Untuk Penyediaan Air Rumahtangga Berkelanjutan Di Lereng Selatan Gunungapi Merapi. J. Manusia Dan Lingkungan. 23(1): 102-110.

Sunaris\& Tallar . (2019). Kajian Nilai Estetika Dan Kualitas Air Dalam Konteks Ekowisata Perairan Berkelanjutan. Jurnal Teknik Sipil. 15(1): 87-148.

Susilo. (2003). Keberlanjutan Pembangunan Pulaupulau Kecil: Studi Kasus Kelurahan Pulau Panggang dan Pulau Pari, Kepulauan Seribu, DKI Jakarta. Disertasi. Sekolah Pascasarjana Institut Pertanian Bogor: Bogor

Thamrin, S. H., Sutjahjo, C. Herison, Biham,S. (2007). Analisis Keberlanjutan Wilayah Perbatasan Kalimantan Barat - Malaysia Untuk Pengembangan Kawasan Agropolitan : Studi kasus Kecamatan Bengkayang Dekat Perbatasan Kabupaten Bengkayang). Jurnal Agro Ekonomi. 25 (2): 103-124.

The International Ecotourism Society. (2015). What is Ecotourism. https://ecotourism.org/what-isecotourism/. Diakses pada 1 Agustus 2021.

Trimanto. (2013) Diversitas pohon sekitar aliran mata air di Kawasan Pulau Moyo Nusa Tenggara Barat. Prosiding Seminar Nasional X Pendidikan Biologi FKIP UNS Surakarta.

Wibowo, A.B., S. Anggoro, \& B. Yulianto (2015). “Status Keberlanjutan Dimensi Ekologi Dalam Pengembangan Kawasan Minapolitan Berkelanjutan Berbasis Perikanan Budidaya Air Tawar Di Kabupaten Magelang ". Jurnal Saintek Perikanan. 10 (2 ): 107-113, 